\title{
Tibetan medicine: a unique heritage of person-centered medicine
}

\author{
Paolo Roberti di Sarsina $\cdot$ Luigi Ottaviani • Joey Mella
}

Received: 4 August 2011 /Accepted: 13 October 2011 /Published online: 12 November 2011

(C) European Association for Predictive, Preventive and Personalised Medicine 2011

\begin{abstract}
With a history going back approximately 2,500 years, the Tibetan medicine, known as Sowa Rigpa in the Tibetan language, is one of the world's oldest known traditional medicine. It originally developed during the preBuddhist era in the kingdom known as Shang Shung. As a traditional medicine, the future development of Tibetan medicine in Western countries is linked to being recognized as a popular and viable healthcare option providing an alternative clinical reality. Its inherent ability to incorparate predictive diagnostics, targeted prevention, and the creation of
\end{abstract}

P. Roberti di Sarsina

Expert for Non-conventional medicine, High Council of Health, Ministry of Health,

Rome, Italy

P. Roberti di Sarsina

Observatory and Methods for Health,

Universtity of Milano-Bicocca,

Milano, Italy

P. Roberti di Sarsina

Charity "Association for Person Centred Medicine",

Bologna, Italy

P. Roberti di Sarsina $(\square)$

Via Siepelunga 36/12,

40141 Bologna, Italy

e-mail: paolo.robertidisarsina@unimib.it

L. Ottaviani

International Shang Shung Institute for Tibetan Studies,

Arcidosso, Italy

J. Mella

Shang Shung Institute,

Conway, USA individualized medical treatment give Tibetan medicine great potential for assessing and treating patients.

Keywords Tibetan medicine · Sowa Rigpa · Chögyal Namkhai Norbu $\cdot$ Predictive diagnosis · Targeted prevention $\cdot$ Individualized treatment

\section{Introduction}

Tibetan medicine is an intricate medicine with a long history of treatment effectiveness. As this medicine begins to spread globally, as with Chinese, Indian Ayurvedic, and other traditional healing modalities, it is important to accurately inform as large an audience to its salient features. Primarily through alliance and collaboration with Western MDs, Tibetan medicine can express its principles in a clear and beneficial way. This would develop through dialogue, research, and ultimately the sharing of intellectual resources. This article is intended as a brief survey of Tibetan medicine's ancient history, its development into the present, and an exploration into future collaborations. Upon review it can be seen that Tibetan medicine is an excellent example of personalized and preventive medicine.

\section{History of Tibetan medicine}

Aspects of Tibetan medicine can be found in ancient cultures as old as 2,500 years. It was in the Kingdom of Shang Shung that practitioners of the Bön Shamanistic religion recorded formal texts describing healing rituals, medical divination, and astrology. Practices such as medical divination lead to much the same nature of treatment. A divination would be made indicating a particular elemental disturbance and a ritual 
remedy prescribed. Divinations would not be limited to medicine but were connected to all actions considered important, such as marriage, beginning a business, and funerals.

The indigenous cultures of pre-Buddhist Tibet also included the use of natural herbal remedies. In particular for wounds, very common when living in harsh environments, various poultices and wraps were used. These basic treatments formed one branch of medicine that when combined with Bon ritual practices offered its people relief. The shamanistic practices, although often relying upon what can be described as superstitious beliefs, also put emphasis upon personal meditation and the balancing of one's body both internally and externally. It is precisely this notion, of the relation of mind and body, that would continue to develop with the introduction of Buddhism into Tibet.

King Songtsen Gampo, in the year $641 \mathrm{CE}$, unified Tibet through military conquest and took two Buddhist wives, princess Bhrikuti of Nepal and princess Wen Cheng of China. The subsequent introduction of Buddhism to the King is thus credited to these two princesses. Although many changes of political power occurred, a steady stream of great masters and scholars of Indian and Chinese Buddhism were welcomed. These masters, such as the famous teacher Padmasambhava, did not dismiss the predominant Bon religious views. Rather they incorporated into the Buddhist view many aspects, including deities of worship and ways of relating to the environment. While collaboration with its neighbors regarding religious teachings increased, so to did knowledge of medicine. In this way a synthesis began to develop, between the indigenous Bon doctors, Ayurvedic Sanskrit texts and doctors, Chinese doctors, and a continued focus on spiritual practice now developed with Buddhist knowledge.

During the subsequent rule of King Trisong Deutsen (755-795 CE) an international conference on medicine was organized, inviting physicians from India, Nepal, Persia, Greece, China, and other neighboring countries. It is thought that from this large sharing of knowledge the great Tibetan physician Yutok Yonten Gonpo then synthesized the essence from each tradition and rewrote the Four Tantras (in Tibetan known as the rGyud bZhi). These texts were followed by many commentaries and additional books, offering greater detail and incorporating ever increasing personal experiences and knowledge. The commentaries combined with oral teachings create the database of Tibetan Medicine's research and development.

\section{Predictive diagnostics, targeted prevention, and the creation of individualized medical treatments}

Tibetan medicine employs many methods to diagnose disease and imbalances. The first and most important aspect is to discover the individual's humoral constitution. Much like the Ayurvedic Doshas, ones humor can be determined as early as infancy. One's humor is determined by the diet and behavior of a child's mother during pregnancy. The three humors are rlung (wind), mkhris pa (fire), and bad kan (earth and water). Differences between the three include for example body type, head shape, digestion, sleeping patterns, and emotional expressions. Each humor pre-disposes the individual to various diseases. For example those with the mkhris pa (fire) constitution are pre-disposed to skin diseases, rashes, and infections. Thus appropriate targeted prevention can be taken predicting diseases before they arise and subsequently avoiding them.

In the same way every aspect of living is seen to predispose an individual to disease. The environment we live, for example warm wet valley or dry cold desert will produce specific imbalances. A Tibetan Doctor can asses this information formulating a predictive diagnosis and individualized treatment plan. Behavior plays the same role. Hard physical labor, or strong intellectual stimulation, although may not immediately manifest a disease, lead to an imbalance. Of course age, gender, and other variables such as pregnancy/childbirth require different targeted prevention. While Tibetan medicine does not formally include targeted prevention towards specific social or economic groups, there is a strong history of the doctor sharing and educated its people. Often doctors educate nomads to collect specific herbs for self treatment and empower communities to help each other with diseases arise. At present doctors and medical schools receive government support for there services as both healers and educators.

Regarding specific diagnosis, digestion is a main focus of Tibetan medicine. The way one digests gives valuable advice to imbalances in the body. Tibetan medicine considers an imbalance in any organ or part of the body to primarily (other then injury, etc.) caused by first an imbalance in digestion. For this reason each individualized medical treatment always incorporates herbal formulas, diet, behavior, and external treatment that directly intend to bring balance and health to the digestive system.

During a Tibetan medicine consultation a doctor will also check the patient's pulse and if possible their urine. Pulse can show the individual's humor, and specifically can diagnose imbalances in each organ. Urine has 9 aspects used for diagnosis, for example color, bubble shape/ formation, sediment, film, and smell. Each aspect can hold keys for diagnosis. Finally a doctor will check one's response to treatment and adjust as needed.

In Tibetan medicine there is no one complete cure. When a doctor treats a patient they work with them to create a long term plan. Often for chronic diseases a treatment may last many months to years. At every step of recovery the 
doctor works closely with the patient and ultimately his or her community to support balance and health. If the patient is a follower of Buddhism or in general interested then the doctor can, in addition to herbal remedies, prescribe meditations or advise exercises such as Tibetan Yantra Yoga. In general the system is scalable to the patients ability to participate and overall interest.

\section{Current situation}

There has been great effort by Tibetan doctors, political leaders, and laypeople in support for Tibetan medicine. What was once limited to family based internships or trainings requiring one to become a monk or nun, has developed more and more into open institutions. In the 17th century Desi Sangye Gyatso, a doctor, scholar, and influential politician founded the Chogpori Medical School in Lhasa, which continued beneficial knowledge contribution up until its collapse during the Cultural Revolution. In 1916 the 13th Dalai Lama established the Men-Tsee-Khang Clinic, school, and pharmacy in Lhasa. Later in exile the 14th Dalai Lama re-established the Men-Tsee Khang in Dharamasala, India [1].

The Men-Tsee-Khang in Daramasala continues to grow, now housing an extensive medical training program, astrological study program, large pharmacies, libraries, and extensive clinics where they have begun incorporating western research methods. The Men-Tsee-Khang is the main location for Tibetans in exile to gain medical training. They admit about two non-Tibetan students for each class, but they must show fluent mastery of both spoken and written Tibetan.

Within Tibet the Qinhai Tibetan Medical School located in Xinning, Amdo region, has emerged as a leading institution for training, research, and collaboration. They offer degree programs in Tibetan Medicine and place graduates at hospitals and clinics throughout Tibet. In addition they have built collaborative programs with conventionally trained MDs in China, integrating traditional and modern techniques to better serve their patients. For example in the Xinning Tibetan Medical Hospital, connected to the school, the majority of doctors are trained in Tibetan medicine, however there are some allopathic MDs who work together as needed. In this way Tibetan medicine is complemented by treatments such as intravenous (IV) fluids or antibiotic prescriptions. In addition there is a growing demand for the obvious benefits imaging techniques such as X-rays and MRI can offer.

Outside of Tibet and India some schools and institutes of Tibetan medicine are emerging. The International Shang Shung Institute for Tibetan Studies, SSI, [2-5] was founded in Italy in 1989 by Chögyal Namkhai Norbu Rinpoche, one of the most important living Masters of the Tibetan
Tradition and holder of the Dzogchen Lineage. It was inaugurated at the Internation Dzogchen Community of Merigar [6], in 1990 by His Holiness the 14th Dalai Lama. It's aim is to deepen the knowledge and understanding of Tibetan cultural traditions in order to ensure their survival and preservation. The Shang Shung Institute has developed Kunye Tibetan Massage programs in Europe and regularly holds conferences and lectures teaching about Tibetan culture and medicine. On September 11th 2010 the ancient Tibetan medical system was the core of the keynote lecture given by Prof. Chögyal Namkhai Norbu Rinpoche in the main hall of the Institute of Anatomy of Bologna University. Prof. Namkhai Norbu delivered a keynote address entitled "Tibetan Medicine, Heritage of the Mankind" $[7,8]$.

\section{Future developments}

There are many points to which Tibetan medicine can strengthen and grow. Its recent history, with the Cultural Revolution, and subsequent dispersal of Tibetan peoples has created both challenges and developments [9-11]. With more interest and transparency of knowledge fruitful alliances can be made. It is imperative that governments and medical organizations recognize Tibetan medicine as a viable and beneficial alternative health care system. It should be recognized after careful review that has a solid history and real strength for helping those in need. This can be accomplished through increased communication between Tibetan doctors and Western MDs. Through continued research and sharing each side could potentially benefit. Then ultimately Tibetan medicine would be recognized at a governmental level, garnering support for additional research, development, and growth.

To few medical texts have been translated. There is an extremely large catalog of documents such as commentaries, practice handbooks, herbal identification texts, and herbal formula transcripts. There only exist a very few number of qualified translators for Tibetan Dharma texts. This developed from an interest in Tibet's spiritual knowledge and experience. However there are even fewer translators of Tibetan medical texts. Like its Dharmic literary language, the medical texts are filled with deep verses, often poetic and cryptic, that without expert explanation, or at least extensive translator training, results in poor or potential dangerous mis-understandings. For this reason an endeavor to train and support translators is extremely important.

It is important to support control and regulations regarding Tibetan doctor training. It is one goal of boards such as ATMA to express clearly the requirements for becoming a Tibetan doctor. In Tibet, and now India, the 
demands a Tibetan medical students endures are rigorous. These standards should extend to all schools throughout the world. It is only when such standards are established, shared with local governments, accepted, then held completely accountable can Tibetan medicine be fully accepted.

Research covering topics from its effectiveness to its ability to integrate with western medicine has begun to develop both in Tibetan regions and the west [12-20]. This research is a good start but to often lacks more rigorous scientific investigations. In addition, while some clinics are being developed outside Tibet and India, it is important to support these projects and help stimulate further initiatives. Some students may be able to attend internships in Tibet or India, but we must also create opportunities in America and Europe. As mentioned before, if Tibetan medical doctors would be able to apply all aspects of its medicine to patients, and if it were able to integrate well with Western medical hospitals, then it is firmly believed great progress in treatment can develop. Of particular interest is that Tibetan medicine has expressed deep understanding of diseases found difficult to treat in Western medicine, such as diabetes, cancer, and mental disturbances, but without systems of acceptance and frameworks for interactions with patients it is very difficult to relieve such situations.

Finally it is important to continue research into the properties and strengths of Tibetan Herbal formulas and ingredients. While research has been conducted covering the ecology and botanical strengths of Tibetan regions $[15$, 21-29], it is important to study more deeply into the pharmaceutical potentials of such materials. A large amount of research is centered around finding active constituents within specific Tibetan medical ingredients [30-41]. This has benefit as it may lead to the development of revolutionary drugs. However the core of Tibetan medicine does not accept single ingredient formulas. Rather it is through combinations of up to 108 or more ingredients that a formula gains its strength. The leading research regarding multi-ingredient formulas come from the Padma Company who produce standardized herbal formulas developed from Tibetan medical knowledge [42-45]. In addition there has been research focusing on pregnancy and birth, in particular using the fomula Zhi Byed 11 [46-48]. It is important that companies such as these and others interested in research be supported by Governments. The Padma Company produces a few products, whereas in totality there are at least 100 individual formulas needing research and development.

\section{Conclusion}

Tibetan medicine is a unique and precious healing modality which deserves recognition and support. It offers it patients carefully designed personalized treatment plans that pro- mote balance with one's environment and ultimately the ability to prevent the occurrence of disease. Tibetan medicine can complement Western medical institutions. Through continued collaboration and research mutual trust can develop between health practitioners. There are many hard working Tibetan Doctors and interested students, but there still exist many challenges, ranging from the need for Governmental recognition and support, to essential needs such as translations of texts and the ability for students to gain valuable clinical knowledge in hospital settings. However with Institutions such as the Shang Shung Institute for the Preservation of Tibetan Culture and The European Association for Predictive, Preventive and Personalised Medicine it is hopeful many great achievements are possible.

\section{References}

1. Men-Tsee-Khang Tibetan Medical \& Astrological Institute of H. H. The Dalai Lama http://www.men-tsee-khang.org

2. The International Shang Shung Institute for Tibetan Studies http:// www.shangshunginstitute.org

3. The Shang Shung Tibetan Healing Center http://www. tibetanmedicinecenter.com/shangshung/Welcome.html

4. The International Shang Shung Institute for Tibetan Studies Multimedia Portal http://www.shangshunginstitute.com/index.php

5. The Shang Shung School of Tibetan Medicine http://shangshung. org/home/school.html

6. Merigar - International Dzogchen Community http://www.dzogchen.it

7. Associazione per la Medicina Centrata sulla Persona OnlusCharity Association for Person Centred Medicine, Bologna, Italy http://www.medicinacentratasullapersona.org

8. Chögyal Namkhai Norbu at Bologna University. The mirror. 2010;106,7.

9. Janes CR. The health transition, global modernity and the crisis of traditional medicine: the Tibetan case. Soc Sci Med. 1999;48:1803-20.

10. Janes CR. The transformations of Tibetan medicine. Med Anthropol Q. 1995;9:6-39.

11. Li J, Yi T, Lai HS, Xue D, Jiang H, Peng HC, et al. Application of microscopy in authentication of traditional Tibetan medicinal plant halenia elliptica. Microsc Res Tech. 2008;71:11-9.

12. Adams V, Miller S, Craig S, Sonam, Nyima, Droyoung, Le PV, et al. Informed consent in cross-cultural perspective: clinical research in the Tibetan autonomous region, PRC. Cult Med Psychiatry. 2007;31:445-72.

13. Cohen L, Warneke C, Fouladi RT, Rodriguez MA, Chaoul-Reich A. Psychological adjustment and sleep quality in a randomized trial of the effects of a Tibetan yoga intervention in patients with lymphoma. Cancer. 2004;100:2253-60.

14. Foggin PM, Torrance ME, Dorje D, Xuri W, Marc Foggin J, Torrance J. Assessment of the health status and risk factors of Kham Tibetan pastoralists in the alpine grasslands of the Tibetan plateau. Soc Sci Med. 2006;63:2512-32.

15. Kala CP. Indigenous uses, population density, and conservation of threatened medicinal plants in protected areas of the Indian Himalayas. Conserv Biol. 2005;19:368-78.

16. Lhamo N, Nebel S. Perceptions and attitudes of Bhutanese people on Sowa Rigpa, traditional Bhutanese medicine: a preliminary study from Thimphu. J Ethnobiolog Ethnomed. 2011;7:3. 
17. Mercer SW, Ager A, Ruwanpura E. Psychosocial distress of Tibetans in exile: integrating western interventions with traditional beliefs and practice. Soc Sci Med. 2005;60:179-89.

18. Mercille J. Media effects on image: the case of Tibet. Ann Tour Res. 2005;32:1039-55.

19. Norsang G, Ma L, Dahlback A, Zhuoma C, Tsoja W, Porojnicu A, et al. The vitamin D status among Tibetans. Photochem Photobiol. 2009;85:1028-31.

20. Sachs E, Rosenfeld B, Lhewa D, Rasmussen A, Keller A. Entering exile: trauma, mental health, and coping among Tibetan refugees arriving in Dharamsala, India. J Trauma Stress. 2008;21 (2):199-208.

21. Anderson DM, Salick J, Moseley RK, Xiaokun O. Conserving the sacred medicine mountains: a vegetation analysis of Tibetan sacred sites in Northwest Yunnan. Biodiver Conserv. 2005;14:3065-91.

22. Ghimire SK, McKey D, Aumeeruddy-Thomas Y. Conservation of Himalayan medicinal plants: harvesting patterns and ecology of two threatened species, Nardostachys grandiflora DC. and Neopicrorhiza scrophulariiflora (Pennell). Biol Conserv. 2005;124:463-75.

23. Kunwar RM, Bussmann RW. Ethnobotany in the Nepal Himalaya. J Ethnobiolog Ethnomed. 2008;4:24.

24. Li T, Zhang H. Application of microscopy in authentication of traditional tibetan medicinal plants of five rhodiola (Crassulaceae) alpine species by comparative anatomy and micromorphology. Microsc Res Tech. 2008;71:448-59.

25. Liu Y, Dao Z, Yang C, Liu Y, Long C. Medicinal plants used by Tibetans in Shangri-la, Yunnan, China. J Ethnobiolog Ethnomed. 2009;5:15

26. Rijal A. Living knowledge of the healing plants: ethnophytotherapy in the Chepang communities from the Mid-Hills of Nepal. J Ethnobiolog Ethnomed. 2008;4:23.

27. Salick J, Zhendong F, Byg A. Eastern Himalayan alpine plant ecology, Tibetan ethnobotany, and climate change. Glob Environ Change. 2009; 19:147-55.

28. Witt CM, Berling NE, Rinpoche NT, Cuomo M, Willich SN. Evaluation of medicinal plants as part of Tibetan medicine prospective observational study in Sikkim and Nepal. J Altern Complement Med. 2009;15:59-65.

29. Zhao ZL, Dorje G, Wang ZT. Identification of medicinal plants used as Tibetan traditional medicine. J Ethnopharmacol. 2010;132:122-6.

30. Dawa Z, Bai Y, Zhou Y, Gesang S, A P, Ding L. Chemical constituents of the whole plants of Saussurea medusa. J Nat Med. 2009;63:327-30.

31. Guo W, Lanzi G, Luobu O, Ma X, Zhen P, Ji Y, et al. An epidemiological survey of alcohol use disorders in a Tibetan population. Psychiatry Res. 2008;159:55-66.

32. Huang B, Ban X, He J, Zeng H, Zhang P, Wang Y. Hepatoprotective and antioxidant effects of the methanolic extract from Halenia elliptica. J Ethnopharmacol. 2010;131:276-81.

33. Li M, Jia Z, Hu Z, Zhang R, Shen T. Experimental study on the hemostatic activity of the Tibetan medicinal herb lamiophlomis rotata. Phytother Res. 2008;22:759-65.
34. Li M, Shang X, Zhang R, Jia Z, Fan P, Ying Q, et al. Antinociceptive and anti-inflammatory activities of iridoid glycosides extract of Lamiophlomis rotata (Benth.) Kudo. Fitoterapia. 2010;81:167-72.

35. Pan L, Zhang XF, Deng Y, Zhou Y, Wang H, Ding LS. Chemical constituents investigation of Daphne tangutica. Fitoterapia. 2010;81:38-41.

36. Wang J, Sun Y, Li Y, Xu Q. Aqueous extract from aerial parts of Artemisia vestita, a traditional Tibetan medicine, reduces contact sensitivity in mice by down-regulating the activation, adhesion and metalloproteinase production of $\mathrm{T}$ lymphocytes. Int Immunopharmacol. 2005;5:407-15.

37. Wang Y, Shi JG, Wang MZ, Che CT, Yeung JH. Mechanisms of the vasorelaxant effect of 1-hydroxy-2, 3, 5-trimethoxy-xanthone, isolated from a Tibetan herb, Halenia elliptica, on rat coronary artery. Life Sci. 2007;81:1016-23.

38. Yeung MF, Lau CB, Chan RC, Zong Y, Che CT. Search for Antimycobacterial constituents from a Tibetan medicinal plant, Gentianopsis paludosa. Phytother Res. 2009;23:123-5.

39. Yi T, Zhao ZZ, Yu ZL, Chen HB. Comparison of the antiinflammatory and anti-nociceptive effects of three medicinal plants known as "Snow Lotus" herb in traditional Uighur and Tibetan medicines. J Ethnopharmacol. 2010;128:405-11.

40. You J, Ding C, Zhu F, Sun X, Li Y, Suo Y. Mass spectrometric identification of Multihydroxy Phenolic compounds in Tibetan herbal medicines. Chromatographia. 2007;65:545-53.

41. Zhou D, Hou Q, Si Q, Liu J, Yang H. Concentrations of the active constituents of the Tibetan folk medicine Qinjiao (Gentiana sect. Cruciata) within and between taxonomic species across the Qinghai-Tibetan Plateau. Chem Biodivers. 2010;7:2088-94.

42. Exner M, Raith M, Holzer G, Gmeiner B, Wagner O, Kapiotis S. Anti-inflammatory mechanisms of the Tibetan herbal preparation Padma 28 in the vessel wall. Forsch Komplementmed. 2006;13:13-7.

43. Hofbauer S, Kainz V, Golser L, Klappacher M, Kiesslich T, Heidegger W, et al. Antiproliferative properties of padma lax and its components ginger and elecampane. Forsch Komplementmed. 2006;13:18-22.

44. Sallon S, Ben-Arye E, Davidson R, Shapiro H, Ginsberg G, Ligumsky M. A novel treatment for constipation-predominant irritable bowel syndrome using Padma ${ }^{\circledR}$ Lax, a Tibetan herbal formula. Digestion. 2002;65:161-71.

45. Weseler A, Saller R, Reichling J. Comparative investigation of the antimicrobial activity of PADMA 28 and selected European herbal drugs. Forsch Komplementarmed Klass Naturheilkd. 2002;9:34651.

46. Miller S, Tudor C, Nyima, Thorsten VR, Sonam, Droyoung, et al. Maternal and neonatal outcomes of hospital vaginal deliveries in Tibet. Intern J Gynaecol Obstet. 2007;98:217-21.

47. Miller S, Tudor C, Thorsten V, Nyima, Kalyang, Sonam, et al. Randomized double masked trial of Zhi Byed 11, a Tibetan traditional medicine, versus misoprostol to prevent postpartum hemorrhage in Lhasa, Tibet. J Midwifery Womens Health. 2009;54:133-41.e1.

48. Wiley AS. Increasing use of prenatal care in Ladakh (India): the roles of ecological and cultural factors. Soc Sci Med. 2002;55:1089-102. 